\title{
Octavio Paz y el ensayo: conciencia y transparencia
}

\author{
Octavio Paz and the Essay: \\ Consciousness and Transparency
}

\author{
Liliana Weinberg ${ }^{1}$ \\ Universidad Nacional Autónoma de México (México)
}

Recibido: 23-03-20

Aprobado: 15-04-20

\section{Resumen}

Octavio Paz fue un lúcido intérprete de su siglo. Este trabajo explora aspectos decisivos de su propia definición como poeta y ensayista, así como de su trayectoria creativa y crítica, altamente representativa de las transformaciones del artista y el escritor contemporáneos. Los ecos de sus experiencias, prácticas de sociabilidad y lecturas, unidos a su sensibilidad y lucidez, hicieron que ya desde sus primeros textos en prosa Octavio Paz contribuyera a la reconfiguración del ensayo como género. Proponemos leer algunos textos del escritor mexicano en diálogo con las reflexiones de varios de los grandes refundadores del ensayo y la crítica en el siglo XX. Su búsqueda de una comunicación profunda entre poesía e historia, su esfuerzo por repensar críticamente la tradición, su exigencia de autenticidad y libertad en el quehacer del escritor, son algunos de los elementos que dieron lugar en sus ensayos a una nueva poética del pensar y a una nueva relación entre conciencia y transparencia.

Palabras-clave: Octavio Paz, ensayo, siglo XX, crítica, conciencia.

\footnotetext{
${ }^{1}$ (weinberg@unam.mx) Doctora en Letras Hispánicas por El Colegio de México. Investigadora titular del Centro de Investigaciones sobre América Latina y el Caribe y profesora en los niveles de licenciatura y posgrado en Letras y Estudios Latinoamericanos de la Universidad Nacional Autónoma de México. Ha sido investigadora principal de varios proyectos dedicados a la teoría, crítica y periodización del ensayo latinoamericano, así como a la relación entre ensayo e historia intelectual. Entre sus publicaciones más recientes se encuentran "José Martí: cronista de lo invisible” (2018), "El Aleph" y las estructuras elementales de la imaginación (2019), "El ensayo como espacio de diálogo intelectual" (2019), "Alfonso Reyes y el Ateneo de la Juventud" (2019), "Redes intelectuales y redes textuales: las revistas del reformismo universitario" (2020). Ha sido directora de la revista Latinoamérica y es actualmente integrante de la Cátedra Alfonso Reyes.

ORCID: https://orcid.org/0000-0002-7006-7812.
} 


\begin{abstract}
Octavio Paz was a visionary thinker of his century. The present work explores decisive traits of his own definition as a poet and essayist and in the opening of a creative and critical trajectory representative of the artist and writer's transformations of the time. The echoes of his experiences, sociability practices, and readings, as well as from his sensitivity and critical lucidity, resulted in that Octavio Paz contributed, since his first prose, to the reconfiguration of the essay as a genre. This article proposes to read some essays of the Mexican writer in dialogue with the reflections of great reformers of the essay and criticism in the twentieth century. The search for a deep dialogue between poetry and history, the effort to critically rethink tradition, the demand for authenticity and freedom in the work of the writer, led to a new poetics of thought and a new relationship between consciousness and transparency.
\end{abstract}

Key-words: Octavio Paz, Essay, XXth Century, Criticism, Consciousness.

\title{
Un ejercicio de lucidez
}

Octavio Paz hizo del ensayo un ejercicio de lucidez. Hombre en su siglo, gran lector, sentidor y entendedor de su época, tocado por la conciencia de la historia y el carácter crítico de su tiempo, Paz logró elaborar muy tempranamente una poética del pensamiento tan compleja y penetrante que lo hizo capaz de refundar uno de los géneros que más frecuentó: el ensayo. Lo hizo además desde un lugar que él consideró "excéntrico" respecto de las grandes capitales del pensamiento occidental, de los modelos literarios y del sistema de los géneros, a través del ejercicio de aquello que él mismo llamó "luz inteligente".

Tuvo Paz acceso a las obras que guardaba la biblioteca de la casa familiar, así como al patrimonio simbólico de lecturas destinadas a los jóvenes ideado por el proyecto educativo vasconceliano. Sumemos a ello su temprana frecuentación, como alumno de San Ildefonso, de la obra de maestros y escritores que lo iniciaron en la lectura de poesía y filosofía y que a su vez lo llevaron a conocer autores como Husserl y corrientes como la fenomenología. Tuvo también acceso, a través de las publicaciones de su época y el diálogo con los jóvenes de su generación, a la lectura de uno de los grandes renovadores del pensamiento que mucho influyó en él: Friedrich Nietzsche. Leyó a modernistas

\footnotetext{
${ }^{2}$ Se pregunta Paz: "¿cuál era mi lugar como poeta hispanoamericano, en la tradición poética de Occidente? [...] Doble excentricidad: era mexicano y escribía en español. Excentricidad de México y de su historia, prolongación de la excéntrica España [...]. Todos los poetas hispanoamericanos han decidido conquistar y asimilar a la tradición europea; todos también han intentado no tanto separarse de ella como transformarla en algo nuevo y radicalmente diferente". Octavio Paz, "La casa de la presencia" [en Obras completas, t. I, México, FCE, 1994], p. 25.
} 
y contemporáneos, asistió a las primeras polémicas entre los distintos grupos (poesía pura versus poesía social), fue tocado por la gran oleada de renovación poética hispanoamericana y combinó la lectura de los clásicos de la poesía en nuestro idioma con los grandes autores en lengua francesa e inglesa. Fue testigo inteligente del surgimiento de grandes temas en tensión como el nacionalismo y el universalismo, el artista y la sociedad. Curioso y agudo lector de los clásicos españoles y europeos, de los mexicanos e hispanoamericanos, tuvo muy tempranamente acceso a la lectura de los grandes poetas que revolucionaron nuestra tradición.

Su viaje a España en 1937 para asistir al II Congreso Internacional de Escritores para la Defensa de la Cultura, precedido por un breve paso por París, le permitió entrar en diálogo con muchas de las grandes figuras de la poesía y el ensayo en lengua española, así como con quienes animaban la revista Hora de España. Esta primera visita resultará decisiva para su propia concepción de la relación entre el arte y la vida, la creación y la moral, y constituirá "una experiencia formativa fundamental", una "obsesión permanente" en él, como modelo de "la posibilidad de una comunión social colectiva en un régimen de libertad"3. Se trata de una época de intenso diálogo poético ${ }^{4}$.

Tocado de una profunda sensibilidad y capacidad para dar nombre y hacer inteligibles las luces y las sombras de su época, Paz contribuyó desde muy temprano a explorar el nuevo lugar de la poesía en un mundo convulsionado y abrió nuevos caminos para la refundación del ensayo y la indagación del sentido.

\section{Reconfiguración del ensayo}

Los comienzos de la obra creativa y crítica de Octavio Paz y su incorporación al campo literario mexicano coinciden con un momento general de reformulación de la voz poética y de refundación del ensayo como un estilo de pensamiento y un modo del saber propio de la tradición literaria. Se trata de la afirmación del ensayo como forma artística, así como de su legitimación como escritura reflexiva.

Octavio Paz abre puertas al ensayo desde sus primeros escritos, y particularmente desde ese texto seminal y de temprana síntesis que es "Poesía de soledad y poesía de comunión” (1942), donde adelanta, a propósito de Quevedo, una idea fundamental: es posible descubrir en el gran autor desengañado "la

\footnotetext{
3 Anthony Stanton, El río reflexivo. Poesia y ensayo en Octavio Paz (1931-1958), México, El Colegio de México-FCE, 2015, pp. 43-44.

4 Véase Christopher Domínguez Michael, Octavio Paz en su siglo, México, Aguilar, 2014, pp. $97 \mathrm{ss}$.
}

Araucaria. Revista Iberoamericana de Filosofía, Política, Humanidades y Relaciones Internacionales, año 22, $\mathrm{n}^{\circ} 43$. Primer semestre de 2020. Pp. 225-249. ISSN 1575-6823 e-ISSN 2340-2199 https://dx.doi.org/10.12795/araucaria.2020.i43.11 
conciencia de la conciencia" "Y Ya desde entonces el concepto de conciencia, y de una conciencia capaz de tomar una distancia lúcida y crítica respecto del mundo y de sí misma, será uno de los grandes motores de su obra reflexiva. Una concepción que se toca con la noción fenomenológica de conciencia intencional, que supuso a su vez una transformación de la idea de subjetividad y contribuyó a reformular el modo de relación entre autor, texto y mundo.

Este mismo ensayo, donde se plantea el vínculo fuerte entre la poesía y la vida, comienza a entretejerse también con la oposición entre "luz y paciencia" planteada por Antonio Machado, retomada en la obra posterior de Paz a través de la imagen de esa "luz inteligente" mencionada en su "Cuarteto", ejercicio de lucidez en la búsqueda del sentido, que será también cifra de su obra.

"Poesía de soledad y poesía de comunión" se relaciona además con su propio quehacer poético, así como con un amplio grupo de trabajos de juventud donde se dan los adelantos de su reflexión sobre la poesía y el arte, que comenzará a elaborar hacia 1951 y culminará en El arco y la lira (1956).

Tempranamente publica el autor sus primeros avances en la comprensión de la cultura mexicana, que aparecerán en periódicos como El Universal a partir de 1943 y pasarán a formar parte más tarde de su primer ensayo de interpretación orgánico: El laberinto de la soledad (1950).

Paz protagoniza también, a través de su colaboración con distintas revistas y la fundación de las propias, un fenómeno general y fundamental para la génesis y consolidación del ensayo en el siglo XX: la dinamización de la circulación de ideas a través de su participación en publicaciones periódicas que él mismo lee y en las que participa. Pensemos en el antecedente de Barandal y en su papel central en Taller; pensemos en su cercanía con los escritores de Hora de España y en general en la importancia que tuvo para él la lectura de Revista de Occidente, Sur, la Nouvelle Revue Française, que fueron laboratorios de proyectos y espacios de sociabilidad - encuentro y debate, confluencia y deslinde- y dinamizadores del conocimiento y la circulación de autores, temas e ideas tan necesarios para la configuración del ensayo. Hombre de su época, es también Paz hombre de revistas y de colaboraciones a través de esas distintas formas discursivas que integran la gran familia de la prosa de ideas: sus prólogos, artículos, notas y comentarios de libros, discursos, conferencias, establecen vasos comunicantes con sus ensayos.

Las operaciones intelectuales que llevará a cabo Paz, su original quehacer en torno a la palabra, denotan su excepcional sensibilidad para la comprensión de su tiempo, para el diálogo, la escucha y el debate de ideas, y nos hacen pensar en su avidez lectora, su vocación por el encuentro intelectual, su interés por la interpretación de los fenómenos y objetos culturales, y muy particularmente

5 "Poesía de soledad y poesía de comunión" [en Octavio Paz, Primeras letras (1931-1943), selección, introducción y notas de Enrico Mario Santí, México, Vuelta, 1988], p. 300.

Araucaria. Revista Iberoamericana de Filosofía, Política, Humanidades y Relaciones Internacionales, año $22, \mathrm{n}^{\circ} 43$. Primer semestre de 2020. Pp. 225-249. ISSN 1575-6823 e-ISSN 2340-2199 https://dx.doi.org/10.12795/araucaria.2020.i43.11 
por la recuperación del tiempo largo de la tradición mexicana puesta en relación con la cultura universal, así como su capacidad para dar nombre a los grandes temas y problemas de nuestra época: repensar el significado de la historia, la cultura, el quehacer poético, el lenguaje. La imaginación, ese surtidor de luz e inteligencia, esa operación sobre la que tanto reflexionó, fue también la que le abrió la posibilidad de encontrar un nuevo camino en su proceso vital e intelectual.

Ya desde sus escritos tempranos hizo Paz contribuciones fundamentales para sentar sobre nuevas bases el ensayo del siglo XX, al situarlo en relación con el problema de la conciencia y la pregunta por el vínculo entre experiencia y sentido. En estos primeros pasos del autor descubrimos también una recuperación del proyecto romántico, tal como él mismo lo retomará en Los hijos del limo, así como una profunda sensibilidad hacia los fenómenos y debates intelectuales de su época. En su obra la interpretación del mundo se toca con la exploración del lenguaje, y el encuentro entre poesía y prosa, la creación y la imaginación, que están en el proyecto literario del romanticismo alemán, están también en Paz. Bien se aplica a su obra en prosa la caracterización de Schlegel: el ensayo como poema intelectual.

\section{El nuevo tiempo del ensayo}

Desde fines del siglo XIX, con la crisis del discurso positivista, la crítica al optimismo del orden burgués, la influencia de autores como Nietzsche, Marx y Freud al tiempo que el surgimiento de nuevas corrientes filosóficas como la fenomenología y el existencialismo, entra también en crisis una forma de la prosa hasta el momento prácticamente confinada al comentario impresionista de los textos o al estudio de las condiciones históricas y sociales que dieron origen a las obras. Pronto comenzará a redefinirse este papel "ancilar" del ensayo y a repensarse la relación entre crítica y creación, entre escritura y vida.

En un libro de enorme importancia para el tema que nos ocupa, Marielle Macé ha estudiado el proceso de autonomización de la prosa literaria que se dará en el siglo XX, cuando el ensayo haga un nuevo ingreso al campo literario, pero ahora para defender su legitimidad y su posibilidad de producir saber, a la vez que mostrar que hay un "estilo de pensamiento" propio de la tradición literaria que se distingue del de la filosofía y de la ciencia ${ }^{6}$.

El ensayo constituye una repuesta específicamente literaria a las nuevas inquietudes intelectuales. Se reinventa, adquiere una nueva visibilidad y legitimidad como manifestación creativa y crítica, redefine su pertenencia

\footnotetext{
${ }^{6}$ Marielle Macé, Le temps de l'essai. Histoire d'un genre en France au XXe siècle, Paris, Belin, 2006, p. 5.
}

Araucaria. Revista Iberoamericana de Filosofia, Política, Humanidades y Relaciones Internacionales, año $22, \mathrm{n}^{\circ} 43$. Primer semestre de 2020. Pp. 225-249. ISSN 1575-6823 e-ISSN 2340-2199 https://dx.doi.org/10.12795/araucaria.2020.i43.11 
genérica y refunda su valor artístico, en una verdadera reconfiguración del sistema de géneros y del campo literario. En la frontera entre la literatura y la retórica, en la frontera entre la literatura y las otras modalidades de producción del conocimiento, el ensayo encuentra un nuevo espacio para la inteligencia crítica y renueva la relación de la literatura con los discursos del saber.

El ensayo defiende así sus fueros como legítima escritura del pensamiento, en cuanto discurso del saber no sujeto a la epistemología y en cuanto tentativa de reconquista de un territorio del que había quedado marginado. El ensayo traduce ahora la contribución de la literatura a la construcción del conocimiento (p. 6). El ensayo se afirma como un género eminentemente cultural y la escritura tiene un papel fundamental en la indagación del saber. En suma: se trata de un proceso de autonomización de la prosa literaria, dedicada ahora a "la comunicación de especies intelectuales"7.

Considero que, tanto en sus respuestas como en sus preguntas, tanto en las síntesis como en las tensiones a que da lugar la "luz inteligente" de su obra, Octavio Paz, este "poeta desdoblado en ensayista, crítico y pensador" (p. 13), resulta un autor representativo del devenir del ensayo en el siglo XX. "Animador de grupos y revistas desde su juventud", "surtidor de proyectos", Anthony Stanton muestra "su decisión de vivir por cuenta propia la aventura del intelectual moderno" (p. 23). Otro tanto podemos decir de un Paz ensayista que vivió por cuenta propia la aventura del ensayo moderno.

\section{Hombre en su siglo}

Nacido en 1914, descendiente de un abuelo liberal que fue militar en época porfiriana y de un padre zapatista que participó en la Revolución como defensor de la reforma agraria, los primeros años de Paz transcurren en un hogar habitado por una biblioteca, donde las preocupaciones políticas se entretejen con la presencia de las letras. El abuelo Irineo había sido gran lector de novelas y escritor él mismo; el padre, Octavio, fue abogado revolucionario y activo periodista. Tocado desde temprano por las discusiones, los debates y la evocación de personajes de la política nacional, en la vida cotidiana del joven Octavio se instalaron las armas y las letras: como él mismo lo recuerda en "Canción mexicana" al evocar la mesa familiar, "el mantel olía a pólvora".

Superada poco a poco la etapa más violenta de la Revolución Mexicana, pronto se vive un nuevo momento de institucionalización y fortalecimiento del Estado, con la presidencia de Cárdenas y Ávila Camacho. México alcanza entonces una cierta atmósfera de calma que contrasta con los acontecimientos de la guerra civil española y la segunda guerra mundial. Todos estos

\footnotetext{
${ }^{7}$ Alfonso Reyes, "Las nuevas artes" [en Obras completas, México, FCE, 1959, t. IX], p. 403.
} 
elementos repercuten sin duda en México y en la vida de Paz, quien había comenzado ya a participar activamente en la escena cultural del país con sus primeras composiciones poéticas y colaboraciones en periódicos y revistas. Conoce además a muchas grandes figuras del mundo literario, desde los Contemporáneos hasta escritores hispanoamericanos, y afectado fuertemente por las duras pruebas que ponía el régimen stalinista a los jóvenes simpatizantes del socialismo y el anarquismo, comenzará muy tempranamente a preguntarse por el papel del artista en su sociedad. Se trata de una época en que la polémica entre los defensores de la poesía pura y la poesía comprometida llega al espacio público. Paz defiende la dignidad del artista como defiende los fueros de la creación y la crítica. Así, en 1943, esto es, en los oscuros años de la segunda guerra mundial, anota: "El escritor, el poeta, el artista, no son instrumentos ni su obra puede ser ese proyectil ciego que muchos suponen. La única manera de derrotar a Hitler y a lo que significa como mal universal es rescatar en el campo de la cultura la libertad de crítica y denuncia".

Fundamentales serán también para él las lecturas no sólo de poesía sino de filosofía y ensayo. En ello tienen particular importancia las revistas y grupos que frecuentó: tal el caso de las ideas de Ortega y Gasset, tanto a través de la lectura de Revista de Occidente como de algunos de sus discípulos, que llegan con el exilio: María Zambrano y José Gaos entre ellos. Y tal es el caso de su profunda afinidad intelectual y afectiva con la revista Hora de España. En textos como "Razón de ser" vinculará la teoría de las generaciones de Ortega con su apasionada indagación del tiempo y de México: "Tal es el sentido de Taller, que no quiere ser el sitio en donde se asfixia una generación, sino el lugar en donde se construye el mexicano, y se le rescata de la injusticia, de la incultura, de la frivolidad y de la muerte" . El interés por la fenomenología de Gaos confluirá a su vez con el que se manifestaba entre círculos filosóficos de México, como es el caso de Samuel Ramos y de aquellos jóvenes pensadores que habrían de integrar el grupo Hiperión.

Ya en un texto tan temprano como "Vigilias: diario de un soñador" (1935), Paz había consignado su preocupación por la existencia de una escisión, un desencuentro entre el hombre y el mundo. El destino humano será, o bien la meditadora tarea de conocer e indagar la realidad, o bien la llamada de la poesía, "heroica disolución del hombre en el mundo"10. En dos conferencias de juventud dictadas en 1942 en Oaxaca y publicadas más tarde como "Poesía y mitología", vuelve Paz -ya influido por la lectura de Roger Caillois-, a indagar la relación entre pensamiento mítico e imaginación, y se preocupa no sólo por

\footnotetext{
${ }^{8}$ Citado por Enrique Krauze [en Octavio Paz. El poeta y la Revolución, México, Debolsillo, 2014], pp. 92-93.

9 "Razón de ser" en Taller, 2 (abril de 1939), p. 154 [p. 34], [edición facsimilar recogida en Revistas literarias mexicanas modernas, México, FCE, 1982, pp. 150-154].

10 "Vigilias: diario de un soñador" [en Octavio Paz, Primeras letras (1931-1943)], p. 64.
} 
"la intervención de la poesía en la creación de los mitos" sino, de manera más radical, por la poesía como "imaginación creadora"11.

En Corriente alterna se referirá a la poesía moderna como "palabra en busca de la Palabra"12. Y me detengo aquí para mostrar que en las primeras exploraciones y deslindes de Paz en torno a la poesía y el sentido del quehacer poético se anuncia otro de los rasgos del ensayo del siglo XX, que buscará, en expresión de Zubiate, "una palabra garante de su decir"13. El lenguaje ingresa como el gran protagonista de la hazaña literaria, y su exploración será una de las tareas más notables de los nuevos escritores. Paz, para quien la palabra cobra un lugar central, vislumbra como pocos este acercamiento a la vez radical y abismal entre poesía y lenguaje, que cambiará el rumbo de la poesía en el siglo XX. Pero la tarea que emprende Paz es aún más compleja, en cuanto se acerca a la palabra desde las nuevas preguntas que aprendió a partir de autores que lo acercaron al pensamiento mítico y al surrealismo etnográfico, o que, como los primeros estudiosos de la prehistoria y el arte prehispánico mexicano, le abrieron los ojos al tiempo largo de la experiencia cultural y a la necesidad de ir en busca de todo un mundo de sentido enterrado.

Es así como comienza a gestarse una primera matriz interpretativa, anunciada en estos textos tempranos, y formalizada en sus primeros grandes ensayos. Esta matriz surgirá de sus propias lecturas, diálogos, tomas de posición respecto de los grandes poetas y filósofos, así como también de la frecuentación de los adelantados en el estudio de la religión, el ritual, la fiesta, la participación. Todo ello le permitirá a su vez redescubrir el mundo precolombino y la tradición mexicana y reflexionar sobre ellos. Paz comenzará a indagar los espacios calificados, los elementos potentes, las zonas de umbral, que permitan atravesar el tiempo en busca de una comunidad de sentido a través del acto poético, erótico, ritual: distintas formas de re-ligación, de re-unión, de fusión: distintas formas de superación del aislamiento en favor del encuentro, la participación, la transparencia.

\section{"Poesía de soledad y poesía de comunión"}

"Poesía de soledad y poesía de comunión”, resultado de la conferencia que impartió en 1942 invitado por la Editorial Séneca para conmemorar el aniversario de San Juan de la Cruz, constituirá un primer esfuerzo de síntesis e integración de muchas de las líneas de diálogo establecidas por el joven escritor, comenzando por ese marcado sentido de responsabilidad del artista

\footnotetext{
11 "Poesía y mitología. El mito" [en ibid.], p. 273.

12 Octavio Paz, Corriente alterna, México, Siglo XXI Editores, 1967, p. 7

13 Jean-Pierre Zubiate, "Essai et poésie au XXe siècle" [en Pierre Glaudes, coord., L'essai: Métamorphoses d'un genre, Toulouse Le Mirail, Presses Universitaires du Mirail, 2002], p. 389.
} 
por la palabra que lo acompañó desde "Ética del artista" ("esta angustia de los jóvenes por saber el sentido de su obra", dirá en $1931^{14}$ ).

Las inquietudes del autor se traducen en la afirmación de una conciencia crítica de su tiempo, que sintetiza todas las exigencias de su época en el contraste entre soledad y comunión, término este último que evoca el ambiente de fraternidad en la poesía que Paz conoció en España. Integra también su preocupación por formas de encuentro, vínculo, religación, participación y calificación que se dan en el ámbito de la religión y de la creación poética. Inspirado en las ideas que le proporcionan las nuevas indagaciones etnográficas sobre pensamiento primitivo y fenomenología de las religiones, y preocupado por las tensiones entre individuo y comunidad, vinculará estas preocupaciones con las distintas formas de conocimiento de la realidad, que conducen a opuestos polares: separación o fusión, especulación o enamoramiento del mundo ${ }^{15}$.

"Soledad" es un término que persigue al propio poeta desde sus primeros años, y que reaparecerá con papel protagónico en poesías y ensayos posteriores (pensemos en textos como "Dialéctica de la soledad", incluido a su vez en El laberinto de la soledad). Es además un término que se hace extensivo al quehacer del creador: "El poeta lírico establece un diálogo con el mundo; en este diálogo hay dos situaciones extremas, dentro de las cuales se mueve el alma del poeta: una, de soledad; otra, de comunión. El poeta parte de la soledad, movido por el deseo, hacia la comunión"16. Este término apunta también al encuentro con lo real, con lo profundo, con lo primero: la conciencia aspira a la transparencia, tanto como al encuentro con los otros y con el sentido de alteridad que habita nuestra propia existencia.

Bien sabido es que posteriormente enlazará Paz la propia conciencia de soledad del sujeto con la soledad del laberinto de la cultura mexicana y con la soledad del hombre contemporáneo. Vinculada, en este caso, con la noción etnográfica y mística de "comunión", en otros casos encontrará resolución simbólica al articularse con el sentido machadiano de "otredad" propio de la "esencial heterogeneidad del ser".

Entre los muchos elementos que podemos extraer de este ensayo infinito, en que se combinan y recombinan distintas intuiciones y "mostraciones", quiero subrayar que su conciencia de lo poético supera esas realizaciones concretas que son los poemas: "La poesía es irreductible a cualquier otra experiencia" (ibid. $)^{17}$.

\footnotetext{
14 Octavio Paz, "Ética del artista" [en Primeras letras], p. 117.

15 Para mayor abundamiento remito a mi trabajo "Luz inteligente: la dimensión antropológica en el ensayo temprano de Octavio Paz" [en Héctor Jaimes, coord., Octavio Paz: la dimensión estética del ensayo, México, Siglo XXI, 2004], pp. 269-311.

16 "Poesía de soledad y poesía de comunión" [en op. cit.], p. 293.

17 "Todo poema se cumple a expensas del poeta", leemos en "Hacia el poema" [en Libertad bajo palabra, Obra poética (1935-1958), México, FCE, 1960], p. 216.
} 
El joven Paz descubre la radical irreductibilidad de la experiencia poética, y procura acercarse a ella como un fenómeno que se hace presente a su conciencia en toda su originalidad, en su carácter extraordinario e irrepetible. Para ello sigue diversos caminos: por una parte, el de su comparación con otros fenómenos y experiencias (mística, magia, religión, amor): "¿la poesía es una expresión de lo absoluto o de la desgarrada tentativa para llegar a él?" (p. 295). Por otra parte, se asoma a la constelación que retomará en El arco y la lira: poesía, poema, poeta, testimonio poético, experiencia, lenguaje, palabra. Emplea distintas expresiones para nombrar esta búsqueda: "diálogo con el mundo", "íntimo deslumbramiento", "la magia de las palabras", "el hechizo del lenguaje, para solicitar a su objeto..." (ibid.).

En todos los casos, ya se asome a la experiencia del poeta, a una experiencia íntima de mundo, o procure caracterizar la propia actividad poética, "actividad subversiva y disolvente" que "sólo existe si se individualiza, si encarna en un poeta", dará un paso más, instaurando el carácter primero de la poesía. Avanza en esta exploración del sentido preguntándose por el quehacer del poeta, pero también por el testimonio poético, "extraño testimonio de la unidad del hombre y el mundo, de su original y perdida identidad". El testimonio del poeta "sólo vale si llega a transformar su experiencia en expresión", y alcanza así "un orden que crea sus propias leyes y su propia realidad: el poema" (ibid.).

Llamativa es la aparición del término "conciencia" en este texto. Y más llamativa aún es la tarea de dar voz y presencia a esa conciencia, que se constituye como fuerza generadora del ensayo:

La poesía es la revelación de la inocencia que alienta en cada hombre y en cada mujer y que todos podemos recobrar apenas el amor ilumina nuestros ojos y nos devuelve al asombro y la fertilidad. Ella revela que la conciencia puede encarnar en todo lo que la rodea y que para lograrlo basta, no negarla, sino anegarla, en las aguas puras del amor. Su testimonio es algo más que un simple testimonio: es la revelación de una experiencia en la que participan todos los hombres y todos los seres, pero que está oculta por la rutina y la diaria amargura [...] la poesía [...] rescata a lo cotidiano de la vulgaridad y unge con lo irreparable al instante (pp. 296-297).

En esta articulación entre distintos niveles, en esta búsqueda de honduras e infinitas relaciones, Paz anuncia una de las claves de su mirada crítica: se asoma a un fondo o magma generador del sentido. Lejos de desembocar en un ensayo plano o estructurado a partir de un equilibrio frío, su reflexión da lugar a una combinatoria incesante, a una cadencia del pensamiento, a un ritmo que se apoya en un contrapunto de 
"enamoramientos y distanciamientos" 18 , y abre a distintas rutas para buscar el surtidor originario de todas las significaciones.

Reiteremos que una de las palabras clave que aquí se perfila (y que será retomada muchas veces por Paz), es la de 'conciencia': conciencia de autor, pero también conciencia de su quehacer; puesta en relación con una situación convertida en presencia y transparencia. Recordemos que con la fenomenología y el existencialismo reingresará con nueva fuerza en el pensamiento filosófico la cuestión de la conciencia intencional en relación con el mundo. Se trata de un término que permite a Paz transitar desde su quehacer individual, desde su propia experiencia y situación, desde la certeza de una soledad desgarrada y lúcida, hacia una mirada de época y un sentido universal.

Si la fenomenología husserliana tuvo particular peso en el primer Paz, la nueva perspectiva fenomenológica, enlazada ya con el existencialismo, tendrá también un papel clave en su contribución a la refundación misma del ensayo. Pensemos en ideas como la de subjetividad trascendental o la concepción del mundo en cuanto mundo vivido, que dieron a su vez lugar incluso a una relectura de Montaigne y a una compleja reinterpretación del vínculo entre ensayo y vida ${ }^{19}$. Al mismo tiempo, al comparar dos experiencias poéticas, la de San Juan y la de Quevedo, la agudeza de Paz abre camino y presagia el desgarramiento existencial del hombre contemporáneo, al referirse a "la conciencia de la conciencia”.

\section{El laberinto de la soledad}

La lectura de este texto nos confirma hasta qué punto el quehacer intelectual de Paz lo coloca como adelantado en la vía del ensayo en cuanto exploración de la relación de la conciencia, la cultura, la historia. Paz se preocupa por hacer un ensayo de interpretación de la vida nacional en el que la literatura tiene mucho para aportar. Hacia los años cuarenta le tocará asistir al despunte de la reflexión sobre lo mexicano, y lo hará tomando distancia de otras propuestas formuladas desde el pensamiento filosófico y el diagnóstico psicológico, a la vez que

${ }^{18}$ Danubio Torres Fierro, “Itinerario de Octavio Paz" [reseña] en Vuelta, 207 (febrero de 1994), p. 36 .

${ }^{19}$ La influencia de la fenomenología en el joven Paz, notada por autores como Omar Astorga, fue confirmada por el propio Paz en Itinerario, y apuntada por varios estudiosos de su obra, como Guadalupe Nettel. La lectura de Husserl llega a conocimiento de Paz tanto desde sus cursos en San Ildefonso y de las inquietudes de la propia tradición filosófica mexicana (Samuel Ramos, etc.), como por el pensamiento español: difundida, como la obra de otros representantes del pensamiento alemán, por Revista de Occidente, posteriormente Gaos será uno de los traductores de Husserl para el Fondo de Cultura Económica. Recordemos que Sartre publicará en 1939 en la $N R F$ un artículo sobre la intencionalidad en la fenomenología de Husserl, tendiendo así un puente entre filosofía y literatura: una "polinización" cruzada entre los ámbitos de la filosofía y la literatura que también llevará a cabo Paz en el ámbito mexicano. 
recuperando lo que la propia poesía tiene para decir al respecto. Se trata de un modo original de desembocar en la cultura desde el mirador de la literatura. Como lo dice Enrique Krauze, "el joven Paz - a pesar de su desarraigo, o debido a él- se había adelantado al menos en dos vertientes: la reflexión poética y la crítica artística"20.

La originalidad de El laberinto de la soledad se confirma ya en los movimientos estratégicos de sentido que plantea desde su primera página, donde la revelación de la propia existencia, el momento de "descubrimiento de nosotros mismos", se pondrá en relación con el surgimiento de una conciencia interrogante: "entre el mundo y nosotros se abre una impalpable, transparente muralla: la de nuestra conciencia"; esa conciencia es propia de los pueblos y los individuos: "¿qué somos y cómo realizaremos eso que somos?": "Despertar a la historia significa adquirir conciencia de nuestra singularidad, momento de reposo reflexivo antes de entregarnos al hacer"'21. El texto se va desplegando, con un movimiento espiralado y asuntivo, para abrirse cada vez más, en un doble surtidor de imágenes-concepto que conduce hacia la historia y el sentido: "rostro y, más tarde, máscara, significación, historia". Esta "preocupación por el sentido de las singularidades de mi país" seguirá, no la vía desapegada de la descripción externa, sino aquella propia del ejercicio de interrogación y contemplación por la cual la conciencia inquisitiva se va dando sus propios motivos y objetos de reflexión en su propio despliegue, sin desatender una esfera particularmente decidora: la creación.

En una prosa ritmada por este recorrido exploratorio de la propia conciencia, Paz recuperará y a la vez renovará no sólo muchos rasgos del ensayo de interpretación latinoamericano, sino también la tradición del ensayo en lengua española, uno de cuyos principales puntos de contacto con América es el que ofreció Ortega y Gasset.

La pregunta por lo propio, que en el caso del ensayo hispánico conduce a la pregunta por las raíces de la cultura española, se convierte en Paz en descubrimiento de la herencia prehispánica y colonial, liberal y revolucionaria. Se trata de un largo viaje del yo por el país del nosotros:

Sí, nos encerramos en nosotros mismos, hacemos más profunda y exacerbada la conciencia de todo lo que nos separa, nos aísla o nos distingue. Y nuestra soledad aumenta porque no buscamos a nuestros compatriotas, sea por temor a contemplarnos en ellos, sea por un penoso sentimiento defensivo de nuestra intimidad (p. 17).

${ }^{20}$ Enrique Krauze, op. cit., p. 78.

${ }^{21}$ El laberinto de la soledad, México, FCE, 1959, pp. 9-10. 
"Nos encerramos en nosotros mismos": el paso del yo al nosotros permite al ensayista enlazar su propia experiencia con la todos los mexicanos, su historia y su cultura. Paz llevará a cabo un recorrido intelectual que es también el de su época, en cuanto, como dice Jean Marcel Paquette, como es notorio en la tradición del ensayo hispanoamericano "La individualidad parece no poder comprenderse a sí misma sino a través de su inserción en la serie histórica y cultural que la ha producido" ${ }^{22}$. De allí ese particular modo de relación del yo y la conciencia con la cultura que habita y que lo habita.

Existe así un elemento que vincula la obra de Paz con una doble línea fundamental del ensayo en lengua española destinada a interpretar lo nacional: tanto la que proviene del desencanto del 98 en España (Ganivet, Unamuno, Ortega, indagarán las claves culturales de la nación que ha perdido sus colonias y el peso de su presencia en el mundo), como la que se genera en la propia América (la preocupación de Borges por el lenguaje, la preocupación de Ezequiel Martínez Estrada y otros autores de ensayo de interpretación por las claves, los principios y los invariantes que conformaron la matriz de la cultura y la vida nacional).

El género se convierte en un buceador de la memoria cultural: el ensayista lleva a cabo un ejercicio de distanciamiento del sujeto a la vez que de retorno a la comprensión de sí y de su cultura a través de su apertura al mundo y las lecturas en que está inmerso. Resuenan aquí los ecos del "yo soy yo y mi circunstancia" orteguiano, así como de su particular lectura del Quijote.

A todo ello aporta nuestro autor un nuevo ingrediente de originalidad, en cuanto se trata no sólo de un pensador que es un gran lector de su propia tradición, sino también de un poeta que llevará más allá sus indagaciones, sus "mostraciones" y demostraciones, hasta alcanzar el tiempo largo de la tradición prehispánica y colonial. Al mismo tiempo Paz enriquecerá su búsqueda con una exploración del lenguaje y los usos de la sociedad en una línea de indagación de las formaciones culturales en una reflexión que llevará a cabo en clave poética: esa fuerte presencia de la voz del poeta no sólo conlleva una "voluntad de estilo" (Juan Marichal), sino también un complejo movimiento que parte del yo en cuanto generador de una reflexión de tipo lírico sobre un corpus cultural (Paquette).

\section{Conciencia y transparencia}

Uno de los grandes poemas de Paz, "El cántaro roto" (1955), guarda, como una nuez, algunas de las claves de la originalidad de sus preguntas, que

\footnotetext{
22 Jean Marcel Paquette, "Forme et fonction de l'essai dans la littérature espagnole" en Études littéraires, 5, 1 (abril de 1972), p. 85. La traducción es mía.
} 
serán también las de sus primeros ensayos, y muestran el devenir de una razón poética: la conciencia se descubre sola, arrojada en un mundo que se revela como radical heterogeneidad, que oculta su sentido, y con el que se propondrá establecer un diálogo. El sujeto se encuentra en un entorno que es ya todo polvo y ceniza: la soledad muda y distante del yacimiento arqueológico, y formula a ese mundo sepultado preguntas capaces de inaugurar respuestas y abrir a su transparencia, recuperar su sentido, conducir hasta el fluir vivo de la vida, el agua y la luz ${ }^{23}$. La conciencia indaga, desde un presente rodeado de silencio, el tiempo largo del gran diálogo del mundo. El poeta nada contra la corriente en busca del sentido sepultado, del manantial del lenguaje:

Dime, sequía, piedra pulida por el tiempo sin dientes, por el hambre sin dientes,

polvo molido por dientes que son siglos, por siglos que son hambres,

dime, cántaro roto caído en el polvo, dime,

¿la luz nace frotando hueso contra hueso, hombre contra hombre, hambre contra hambre,

hasta que surja al fin la chispa, el grito, la palabra,

hasta que brote al fin el agua y crezca el árbol de anchas hojas de turquesa?

El poeta descubre así que sólo la posibilidad de tender un puente de preguntas y respuestas con el mundo y el esfuerzo de recobrar las palabras harán posible remontar el sentido: se trata de un largo viaje hacia sí mismo que es a la vez un largo viaje hacia el origen, hacia el manantial de las palabras, hacia la transparencia del sentido, emprendido por una conciencia sola y desgarrada:

hay que soñar hacia atrás, hacia la fuente, hay que remar siglos arriba, más allá de la infancia, más allá del comienzo, más allá de las aguas del bautismo, echar abajo las paredes entre el hombre y el hombre, juntar de nuevo lo que fue separado, vida y muerte no son mundos contrarios, somos un solo tallo con dos flores gemelas, hay que desenterrar la palabra perdida, soñar hacia dentro y también hacia afuera [...] hacia allá, al centro vivo del origen, más allá de fin y comienzo ${ }^{24}$.

Escrito por los mismos años que El laberinto, este poema emprende también una búsqueda del origen que es a la vez la búsqueda de la palabra perdida y de la transparencia por parte de una conciencia desgarrada.

${ }^{23}$ Coincido con autores que, como Maya Schärer, Anthony Stanton y Guillermo Sheridan, ven una relación fuerte y de mutua correspondencia entre poesía y ensayo en Octavio Paz.

24 "El cántaro roto" [en Octavio Paz, La estación violenta, en Obras completas, t. XI, México, FCE, 1994], pp. 213-215. 


\section{Lo poético y lo poetizado}

Hombre de su tiempo, sensible a los grandes temas y problemas de su época, Paz emplea la inteligencia y la visión poética como instrumentos para penetrar lo real, y en este esfuerzo por encontrar un nuevo punto de mira coincide con algunos de los grandes exploradores del ensayo, el arte y la cultura contemporáneos, a quienes el romanticismo y la Lebensphilosophie de Simmel heredaron sus grandes preguntas por la relación entre la vida y la forma. Las reflexiones de Paz apuntan a ese umbral entre aquello que Benjamin llama "lo poético y lo poetizado". Una preocupación que es evidente también en el joven Lukács, para quien el ensayo es un juicio que debe cumplir con la exigencia de sacar de sí y fundar sus propios valores juzgadores ${ }^{25}$, y para quien la forma artística es "la ritmización de lo que hay que decir [...], la intensificación de los últimos sentimientos, vividos con la mayor fuerza, hasta que alcanzan significación independiente" ${ }^{26}$. Paz indagará ese espacio decisivo en que la vida deviene forma.

Desde su propio quehacer reflexivo vislumbra Paz la necesidad de asomarse a la zona en que concurren esas instancias que Castoriadis -a quien conocerá personalmente varios años después- 1lama lo instituyente y lo instituido y hará del ensayo un programa de indagación profunda del mundo de los valores y comprensión del imaginario fundante de la vida cultural: "El imaginario no es entonces un mero conjunto de representaciones o la así llamada 'mentalidad colectiva', sino sobre todo, tal como sostiene Castoriadis, el 'magma' en virtud del cual la sociedad se articula y se autoconstituye"27.

Una de las constantes en la tarea ensayística de Paz será ese esfuerzo por ir en busca del sentido a través de la exploración del vínculo entre la vida y el lenguaje. Su interés por encontrar los puntos límite y de articulación entre naturaleza y cultura, experiencia individual y sentido comunitario, le permitirá proponer una nueva interpretación del lenguaje y la palabra, colocada en ese punto de articulación radical en que una cultura instituye una visión de mundo.

A todo ello añadimos que, a diferencia de muchos de estos pensadores, predominantemente provenientes del campo de la filosofía -aun cuando es en ellos evidente la nostalgia por la poesía-, encontraremos un nuevo y singular ingrediente en el caso de Paz, quien fue capaz de alimentar su reflexión ensayística con su propia experiencia poética, y de allí esa sorprendente aventura del pensamiento que protagonizó.

La relación entre poesía y prosa es en Paz compleja y diversa. Por una parte, ya desde temprano lo acompaña el interés por hacer una lectura crítica-que en

${ }^{25}$ Georg Lukács, "Sobre la esencia y forma del ensayo" [en El alma y las formas. Teoría de la novela, México, Grijalbo, 1985], p. 38.

${ }^{26}$ Georg Lukács, "Riqueza, caos y forma: un diálogo sobre Laurence Sterne" [en op. cit..], p. 228.

27 Omar Astorga, "La filosofía de Octavio Paz" en Araucaria, 6, 11 (2004), p. 124. 
la mayoría de los casos alcanza las dimensiones de una lectura de escritor-, de muchos de los poetas que lo impresionaron y con quienes entabló a través de la prosa un diálogo de buenos entendedores. Dedica ensayos puntuales y orgánicos a algunos de los poetas que más admiró (Sor Juana o Villaurrutia, Quevedo o Machado), así como integra el tratamiento de muchos poetas a la interpretación de procesos más amplios (El arco y la lira, Los hijos del limo).

Siguiendo el impulso de la mirada, también cercano a la postura fenomenológica, escribe Paz notables textos interpretativos sobre artistas plásticos, sin anegarse desde luego en la mera caracterización y descripción de sus obras: logra asomarse a los principios y procesos creativos que las generan, a la vez que a las respuestas que los creadores dan a su tiempo. A este respecto, veo en los ensayos que dedica a poetas y artistas como Antonio Machado y Rufino Tamayo un particular e intenso esfuerzo de comprensión de la creación desde el interior de las propuestas creativas individuales, desde ese punto de articulación fundamental entre el magma de lo indeterminado y la composición o dotación de forma, acudiendo para ello a dos figuras que tan cerca estuvieron de sus propias inquietudes vitales y estéticas.

\title{
La esencial heterogeneidad del ensayo
}

En el primoroso texto que dedica a Antonio Machado, contenido en Las peras del olmo, abunda Paz en una idea que lo acompañará a lo largo de los años: "la esencial heterogeneidad del ser", ligado a su vez a otras cuestiones fundamentales, como la otredad y la relación entre el poeta y el tiempo ("encerrado en su soledad, el poeta canta el canto del tiempo"28):

\begin{abstract}
Machado ha intuido los temas esenciales de la poesía y la filosofía de nuestro tiempo. Su visión del ser como heterogeneidad y otredad me parece que toca la entraña misma, el tema central de la filosofía contemporánea; su desconfianza frente a la dialéctica hegeliana -fuente de tantos males de nuestra época- y su insistencia en examinar con ojos nuevos el principio de identidad, muestran, asimismo, y con gran hondura, que la crítica que se hace la filosofía a sí misma y a sus fundamentos coincide con las aspiraciones más altas de la poesía (p. 173).
\end{abstract}

Machado es también modelo de comprensión del desgarramiento del artista de su época: "Nadie ha vivido entre nosotros con mayor lucidez el conflicto del poeta moderno, desterrado de la sociedad y, al fin, desterrado de sí mismo, perdido en el laberinto de su propia conciencia [...]. Todos hemos perdido la voz común" (ibid.).

${ }^{28}$ Octavio Paz, “Antonio Machado" (1951) [en Las peras del olmo, Barcelona, Seix Barral, 1971], p. 172.

Araucaria. Revista Iberoamericana de Filosofia, Politica, Humanidades y Relaciones Internacionales, año $22, \mathrm{n}^{\circ} 43$. Primer semestre de 2020. Pp. 225-249. ISSN 1575-6823 e-ISSN 2340-2199 https://dx.doi.org/10.12795/araucaria.2020.i43.11 
Paz quedará marcado no sólo por la grandeza artística de los poetas de la guerra civil y del exilio, sino también por el sentido ético que caracterizó el quehacer de toda esa generación genial, lúcida y comprometida con la palabra. Paz dice de manera inmejorable:

La claridad de Machado es vertiginosa. Leerlo es ahondar, penetrar en una transparencia sin fin: en una conciencia que se refleja a sí misma. Las máscaras de Machado parecen decirnos que son algo más que máscaras: son las formas en que se ha fijado un rostro perpetuamente móvil [...]; sabe que sólo puede revelarse en otro, en un contrario que es un complemento: el poeta en el filósofo, el enamorado en la ausencia, el solitario en la muchedumbre, el prisionero del yo en el tú de la amada o en el nosotros del pueblo (p. 168).

Es así como el tema de la esencial heterogeneidad del ser, el otro, su contrario, su complemento, planteado por Machado y reinterpretado ahora por el mexicano, cobra un nuevo y luminoso sentido al dar lugar a una reflexión sobre la propia conciencia, siempre nostálgica de transparencia.

\section{El ensayo y la crítica}

Se encuentra también en Paz otra de las grandes líneas del ensayo contemporáneo: su no menos compleja relación con la crítica. Si ya desde Montaigne el ensayo se muestra como puesta en relación y mutua alimentación del sujeto y el juicio, la lectura y la escritura, una vez más el siglo XX aporta (Paz lo ha dicho muy bien), la llegada de una conciencia crítica.

Agudo lector, siempre se mostró Paz interesado en trazar historias, genealogías, seguir líneas, reflexionar sobre tradiciones y procesos en el campo de la poesía como escritor y como crítico. Su visión del quehacer desgarrado del escritor contemporáneo se nutre, entre otros, de una aguda intuición, consignada ya en "Poesía de soledad y poesía de comunión", donde descubre en Quevedo la conciencia lúcida, desengañada, de un poeta cuyo quehacer se aleja radicalmente de la posibilidad de conciliación total con el mundo propia de un místico como San Juan de la Cruz.

En Paz, como en Borges, encontramos una aguda y creativa puesta en relación de crítica y creación, lectura y escritura: continuidad y ruptura entre estos quehaceres. Por momentos unión, fusión de estos pares de opuestos, y por momentos toma de distancia lúcida y radical. El examen de las obras genera, además, como lo dice en Los hijos del limo, un espacio intelectual, un espacio de encuentro, un espacio en que concurren crítica y creación:

Carecemos de un "cuerpo de doctrina" o doctrinas, es decir, de ese mundo de ideas que, al desplegarse, crea un espacio intelectual: el ámbito de una obra, la 
resonancia que la prolonga o la contradice. Este espacio es el lugar de encuentro con las otras obras, la posibilidad del diálogo entre ellas. La crítica es lo que constituye eso que llamamos una literatura y que no es tanto la suma de las obras como el sistema de sus relaciones: un campo de afinidades y oposiciones. Crítica y creación viven en perpetua simbiosis [...]. La misión de la crítica [...] no es inventar obras sino ponerlas en relación [...]. En este sentido, la crítica tiene una función creadora: inventa una literatura (una perspectiva, un orden) a partir de las obras ${ }^{29}$.

En una concepción cercana a la de Benjamin, dirá también que "La poesía moderna es inseparable de la crítica de lenguaje que, a su vez, es la forma más radical y virulenta de la crítica de la realidad" (p. 5).

\section{Un quehacer de palabras}

En otra vuelta de la espiral, Paz indaga a través del ensayo las condiciones de lucidez que hacen posible explorar la dimensión creativa y crítica de la palabra, en su carácter a la vez originario e interpretable. La palabra-opacidad y transparencia, intransitividad y transitividad- se vuelve central en la obra de Paz, quien se preocupa por la relación entre el lenguaje, el tiempo y el sentido, y busca, desde el carácter segundo de la palabra ensayística, salvar el carácter primero de la palabra poética ${ }^{30}$.

Creador y crítico él mismo, interpreta el propio quehacer poético en su hacerse, sin reducir su especificidad, sin dejar de tener conciencia de la esencial heterogeneidad del discurso ensayístico respecto del poético, al tiempo que busca salvar dicha distancia. Esto nos conduce a los innumerables textos de Paz -verdaderos surtidores de sentido- en que confluyen poesía y prosa, así como a El arco y la lira, pensado en un primer momento como un trabajo crítico en la línea de lo sugerido por Reyes, y que finalmente derrotó sus propios límites para convertirse en una vasta reflexión sobre el sentido de la poesía.

Uno de los elementos que Paz vio con particular penetración y resultan seminales en su propia obra es -como ya lo anticipó A. W. Schlegel- que "la poesía está originariamente en el lenguaje" ${ }^{1}$. Su exploración "fenomenológica" de las palabras; su permanente preocupación por lo nombrable y lo inteligible; su empresa de desentrañar la relación entre poesía e historia; su ejercicio constante por dotar de la voz más acertada a la conciencia pensante; su indagación de los laberintos y abismos del lenguaje e incluso su acertada apelación a "las

\footnotetext{
${ }^{29}$ Octavio Paz, Corriente alterna, México, Siglo XXI Editores, 1967, pp. 39-41.

${ }^{30}$ Véase Liliana Weinberg, Pensar el ensayo, México, Siglo XXI Editores, 2007.

31 Philippe Lacoue-Labarthe y Jean-Luc Nancy, El absoluto literario. Teoría de la literatura del romanticismo alemán, Buenos Aires, Eterna Cadencia Editora, 2012, p. 434. Para el romanticismo en Paz véase también Raúl D. Motta, "Octavio Paz y la revelación poética de la complejidad".
} 
palabras de la tribu" para dar nombre a sus propios libros (¿cómo no celebrar expresiones tan decidoras como "Libertad bajo palabra", "Las peras del olmo", "Puertas al campo" o "El signo y el garabato"?), constituyen un primer anuncio de su poderosa indagación de la poesía en el seno del lenguaje.

La convergencia entre poesía y ensayo se articula en Paz con su toma de conciencia del lenguaje y su indagación de los objetos culturales en busca de transparencia: ese amplio mundo que en su maravilla y especificidad se encontraba sumergido por siglos, y del cual nos ofrecieron un primer atisbo los románticos. El lenguaje deja de ser un componente más de la obra, para acompañar al fenómeno de autogeneración del acto poético y comienzan a redefinirse las fronteras entre creación y reflexión. También se redefinen lector y poeta, en ese acto fundacional, el nombrar, que salva al sentido del caos, el silencio y lo ininteligible. Dice Paz:

\begin{abstract}
Al nombrar, al crear con palabras, creamos eso mismo que nombramos y que antes no existía sino como amenaza, vacío y caos. Cuando el poeta afirma que ignora "qué es lo que va a escribir" quiere decir que aún no sabe cómo se llama eso que su poema va a nombrar y que, hasta que sea nombrado, sólo se presenta bajo la forma de silencio ininteligible. Lector y poeta se crean al crear ese poema que sólo existe por ellos y para que ellos de veras existan ${ }^{32}$.
\end{abstract}

Paz intentará decir ese nombrar, desplegará permanentemente esta relación entre ambos planos, y la tensará hasta sus límites para confrontar al ensayo con su vocación crítica y su vocación creativa, que le permitirá encontrar nuevos puntos de contacto y mutuo enriquecimiento con la poesía. El ensayista elige un camino que nos recuerda el de la fenomenología de Husserl en cuanto busca llegar a la poesía misma sin reducción de ningún tipo, y apela a la conciencia y al carácter intencional de la búsqueda de sentido, a la vez que, como lo muestra Stanton, en su preocupación por el tiempo y la historia nos acerca a Heidegger.

Con El arco y la lira inaugura Paz un camino original de interpretación del lenguaje y el acto poético, su carácter originario, su vínculo con la palabra y el ritmo. El ensayo resulta así - una vez más con Zubiate- el lugar donde la palabra interpretativa de la poesía puede reaprehender su sentido. En cuanto escritura interpretativa que valida performativamente los descubrimientos de la poesía y se convierte en justificación a posteriori de una visión a priori de la intelección verbal, el ensayo puede también convertirse en espejo del poema, y de este modo evitar una de sus mayores tentaciones, el narcisismo: "una misma fuente alimenta el trabajo del ensayo y de la poesía del siglo XX: la pregunta que ellos formulan desde el principio sobre la validez representativa -cognitiva o expresiva-del trabajo escritural", dice Zubiate. El ensayo y la poesía marchan así hacia ese punto en común: su convergencia en y por la palabra.

${ }^{32}$ Octavio Paz, El arco y la lira, México, FCE, 1956, p. 174.

Araucaria. Revista Iberoamericana de Filosofia, Política, Humanidades y Relaciones Internacionales, año 22, no 43. Primer semestre de 2020. Pp. 225-249. ISSN 1575-6823 e-ISSN 2340-2199 https://dx.doi.org/10.12795/araucaria.2020.i43.11 
A todos estos elementos podemos agregar la peculiar sensibilidad de Paz hacia cuestiones como la alteridad y la historicidad, que le permiten complejizar aún más su reflexión. Considero que las palabras que siguen, y que aparecen en El arco y la lira, son a la vez un manifiesto, un programa, una respuesta sintética a la pregunta por el lugar del poeta y la poesía en el mundo contemporáneo. El ensayista-poeta interpreta:

El poema, ser de palabras, va más allá de las palabras y la historia no agota el sentido del poema; pero el poema no tendría sentido -y ni siquiera existenciasin la historia, sin la comunidad que lo alimenta y a la que alimenta. Las palabras del poeta, justamente por ser palabras, son suyas y ajenas. Por una parte, son históricas: pertenecen a un pueblo y a un momento del habla de ese pueblo: son algo fechable. Por la otra, son anteriores a toda fecha: son un comienzo absoluto [...].

La condición dual de la palabra poética no es distinta a la de la naturaleza del hombre, ser temporal y relativo pero lanzado siempre a lo absoluto. Ese conflicto crea la historia ${ }^{33}$.

De allí otro de los prodigios de la obra de Paz: una obra dedicada a nombrar, pero también a explorar el significado del nombrar, conciencia orientada siempre a la transparencia.

Ya desde el propio título, "Poesía y poema", el primer capítulo de El arco y la lira nos plantea una operación de impresionante lucidez, para cuya justa valoración es necesario recordar no sólo la visionaria tarea emprendida por el romanticismo alemán sino también lo planteado, ya en el siglo XX, por Walter Benjamin: el confinium entre lo poético y lo poetizado. De allí el sentido de la tarea abismal que emprende Paz, quien ingresa a la reflexión sobre la poesía desde su propio quehacer como poeta: "Habrá, pues, que interrogar a los testimonios directos de la experiencia poética. La unidad de la poesía no puede ser asida sino a través del trato desnudo con el poema" (p. 14).

Paz opta por una presentación "fenomenológica" del tema, a partir de la cual desfila una serie de intuiciones o iluminaciones fundantes, que entran en tensión entre ellas, dando lugar a un ritmo del decir y del reflexionar, que pronto se hace presente, nombrando esa "operación capaz de cambiar al mundo..." (ibid.). La presentación de opuestos en tensión permite generar a su vez una cadencia y un espacio de encuentro activo en que los binomios conviven, chocan, dicen más, generan ritmo, producen un plus de sentido: "Pan de los elegidos; alimento maldito", "La poesía revela un mundo, crea otro" (ibid.). Los grandes temas de Paz confluyen también en esta primera presentación: "voz del pueblo, lengua de los escogidos, palabra del solitario".

33 Octavio Paz, El arco y la lira, pp. 189-193.

Araucaria. Revista Iberoamericana de Filosofia, Politica, Humanidades y Relaciones Internacionales, año $22, \mathrm{n}^{\circ} 43$. Primer semestre de 2020. Pp. 225-249. ISSN 1575-6823 e-ISSN 2340-2199 https://dx.doi.org/10.12795/araucaria.2020.i43.11 
En diálogo con el lector y con él mismo, plantea el ensayista:

Al preguntarle al poema por el ser de la poesía, ¿no confundimos arbitrariamente poesía y poema? [...]

Un poema es una obra. La poesía se polariza, se congrega y aísla en un producto humano; cuadro, canción, tragedia. Lo poético es poesía en estado amorfo; el poema es creación, poesía erguida. Sólo en el poema la poesía se aísla y revela plenamente $[\ldots]$. El poema no es una forma literaria sino el lugar de encuentro entre la poesía y el hombre [...] ¿Cómo asir a la poesía si cada poema se ostenta como algo diferente e irreductible? (pp. 14-15).

Paz toma nuevamente una actitud fenomenológica para ir en busca de lo irreductible y asomarse a la relación entre la poesía y el poema.

Otra de las cuestiones que Paz intuyó como pocos es la del sentido, y para acercarse a él incorpora a la discusión ejemplos provenientes de distintos tiempos y espacios de la cultura y la experiencia humana, entre los que me interesa destacar los provenientes del mundo prehispánico. Es así como nos encontramos con otro de los componentes más deslumbrantes del pensamiento de Paz: su especial sensibilidad por el rescate del tiempo largo de la cultura mexicana, que se nutre en primerísimo lugar de su propia experiencia y su temprano despertar de una perspectiva antropológica, histórica, lingüística y arqueológica. Tiene que ver también con su trato con las vanguardias y el surrealismo etnográfico, así como con su particular lectura y comprensión de los primeros grandes estudiosos del arte y la cultura prehispánicos.

La preocupación por el sentido se enlaza además en Paz con otros elementos que le aportó su temprano acercamiento a la fenomenología -conciencia, intencionalidad, direccionalidad, dotación de valor-, compañeros todos de esa constante tarea que consiste en el gran impulso que anida en su obra: la palabra va en busca del sentido, la conciencia va en busca de la transparencia.

\section{El alto surtidor de la creación}

Para concluir, me interesa resaltar otra de las muchas vías y contribuciones fundamentales que inauguró Paz para el ensayo: la que se deriva de afirmar "los privilegios de la vista" 34 y abrir la mirada a la interpretación del arte prehispánico, colonial y contemporáneo. Fundará Paz no sólo una línea de interpretación de las obras artísticas y los objetos culturales que él mismo continuará explorando a lo largo de su vida, sino también un nuevo modo de

34 Tomo esta expresión del título que el propio Paz, inspirado a su vez en Góngora, adopta para agrupar sus ensayos sobre arte. Véase Obras completas, tomo VI, Los privilegios de la vista I: Arte moderno universal y tomo VII, Los privilegios de la vista II: Arte de México, México, FCE, 1994.

Araucaria. Revista Iberoamericana de Filosofí, Política, Humanidades y Relaciones Internacionales, año 22, $\mathrm{n}^{\circ} 43$. Primer semestre de 2020. Pp. 225-249. ISSN 1575-6823 e-ISSN 2340-2199 https://dx.doi.org/10.12795/araucaria.2020.i43.11 
puesta en relación de la palabra y la imagen que es mucho más que mera crítica o comentario de obras artísticas: se trata de textos que encuentran a su vez su propia forma y con ello su propia legitimidad.

Particular importancia tiene la indagación que hizo Paz de la obra de Rufino Tamayo, a quien vio como uno de sus pares en las búsquedas y las respuestas artísticas. Atendamos al primer ensayo sobre el artista, firmado en París en 1950. Paz atenderá tanto a la obra del pintor como a su capacidad de retomar y renovar la tradición y conducirnos a "una reflexión sobre la pintura y la Revolución Mexicana": ese momento en que "el país se encuentra a solas consigo mismo", hecho que supone "una revelación del subsuelo histórico de México", un salto a los orígenes y una búsqueda de la contemporaneidad ${ }^{35}$. La Revolución abre al intelectual Paz a la reflexión sobre la historia de México y a cuestiones como tradición, modernidad, nacionalismo y universalidad, y a partir de allí el ensayo se abre a muchas dimensiones: la historia, la pintura mexicana, la prodigiosa obra de Tamayo...

Examinará la plástica mexicana a partir de otro cruce de temas y tiempos:

"El descubrimiento de las artes precortesianas y populares también es un resultado de la curiosidad de la estética occidental [...]. Nuestra pintura es un capítulo del arte moderno. Pero, asimismo, es la pintura de un pueblo que acaba de descubrirse a sí mismo y que, no contento con reconocerse en su pasado, busca un proyecto histórico que lo inserte en la civilización contemporánea” (pp. 192-193).

Una vez más, el tiempo largo de la historia mexicana se toca con las exigencias del presente.

Paz encuentra en el principio solar-lunar un fundamento para la comprensión de la clave creativa de Tamayo, un punto de encuentro entre la imaginación del artista y el imaginario cultural que se convierte en un principio activo, generativo, de la propia obra del artista y enlaza las distintas dimensiones de su vida creativa: "Toda la obra de Tamayo parece ser una vasta metáfora. Naturalezas muertas, pájaros, perros, hombre y mujeres, el espacio mismo, no son sino alusiones, transfiguraciones o encarnaciones del doble principio cósmico que simbolizan el sol y la luna” (p. 202).

La ensayista propicia a través del despliegue del texto una experiencia de participación con el lector al tiempo que genera una "ilusión de presencia"; con tal propósito la palabra coopera con la imagen, a la que, de alguna manera, completa: el ensayo se convierte en un "modelo de lectura" de la imagen". Se confirman de este modo los privilegios de la vista y se recupera otro componente creativo fundamental:

${ }^{35}$ Octavio Paz, "Tamayo en la pintura mexicana” [1950], Las peras del olmo, pp. 191.

${ }^{36}$ Efrén Giraldo, "Ensayo e imagen. De la ilusión de presencia a la creación relacional” [en Liliana Weinberg, coord., El ensayo en diálogo, vol. I, México, CIALC, UNAM, 2017], pp. 205-209. 
Por gracia de esta comprensión del ritmo vital, su pintura es un signo más en el cielo de una larga tradición. La naturalidad con que Tamayo reanuda el perdido contacto con las viejas civilizaciones precortesianas lo distingue de la mayor parte de los grandes pintores de nuestro tiempo, mexicanos o europeos (p. 202).

Como ha escrito Marielle Macé, con el ensayo del siglo XX asistimos a una redefinición fenomenológica de la subjetividad. Existe una "enunciación fenomenológica" que hace que el texto se pronuncie en primera persona al tiempo que se escribe con los ojos: la mirada ha llegado a ser un útil cognitivo y las imágenes confirman su dimensión heurística, en cuanto cumplen la función del concepto (p. 201). El escritor mexicano ha llevado estos elementos a un máximo de rendimiento estético.

"La conciencia, la transparencia", leemos en su poema "Más allá del amor": la fuerte presencia de ambos términos en la obra de Paz llevó ya a varios estudiosos a retomar estos términos desde distintos puntos de vista. En el presente trabajo se ha propuesto contemplarlos en su mutua y compleja relación.

Octavio Paz reformula el quehacer del ensayo e indaga nuevos modos de despliegue de la conciencia en busca de la transparencia; explora un nuevo espacio de encuentro y participación con el lector; traza un nuevo itinerario para ir en busca del sentido; funda un original modo de pensar los componentes culturales y los motivos a la vez temporales y universales de la reflexión.

$\mathrm{El}$ autor vislumbra las zonas de confluencia y tensión entre lo instituyente y lo instituido, lo poético y lo poetizado; indaga el lenguaje a partir del lenguaje; reconoce el lugar central de la palabra, en una exquisita percepción de los muchos niveles a que nos conduce la pregunta por el sentido: la imagen del "alto surtidor", anuncio de la fluencia del sentido en el tiempo, espacio nunca colmado de encuentro entre conciencia y transparencia, entrevista y nombrada por el poeta, convertida en principio sensible e inteligible por el ensayista, corresponde tanto a la relación de la vida con el artista como a la relación del artista con la vida. 


\section{Referencias bibliográficas:}

Astorga, Omar, "La filosofía de Octavio Paz", Araucaria, 6, 11 (2004), pp. 121-145.

Domínguez Michael, Christopher, Octavio Paz en su siglo, México, Aguilar, 2014.

Giraldo, Efrén, "Ensayo e imagen. De la ilusión de presencia a la creación relacional", en El ensayo en diálogo, vol. I, México, CIALC, UNAM, 2017, pp. 203-239.

Jaimes, Héctor, coord., Octavio Paz: la dimensión estética del ensayo, México, Siglo XXI Editores, 2004.

Krauze, Enrique, Octavio Paz. El poeta y la Revolución, México, Debolsillo, 2014.

Lacoue-Labarthe, Philippe y Jean-Luc Nancy, El absoluto literario. Teoría de la literatura del romanticismo alemán, trad. Cecilia González y Laura Carugati, Buenos Aires, Eterna Cadencia Editora, 2012.

Lukács, Georg, "Sobre la esencia y forma del ensayo", en El alma y las formas. Teoría de la novela, trad. Manuel Sacristán, México, Grijalbo, 1985.

Macé, Marielle, Le temps de l'essai. Histoire d'un genre en France au XXe siècle, Paris, Belin, 2006.

Marichal, Juan, La voluntad de estilo (teoría e historia del ensayismo hispánico) Barcelona, Seix Barral, 1957.

Motta, Raúl Domingo, “Octavio Paz y la revelación poética de la complejidad humana en el encuentro entre la poesía, la revolución y la religión en el Romanticismo" [dossier], Buenos Aires, CIUEM, 2013, pp. 1-40.

Nettel, Guadalupe, Octavio Paz. Las palabras en libertad, México-Madrid, El Colegio de México-Taurus, 2014.

Paquette, Jean Marcel, "Forme et fonction de l'essai dans la littérature espagnole", Études littéraires, 5, 1 (abril de 1972), pp. 75-88. Disponible en línea: https://www.erudit.org/fr/revues/etudlitt/1972-v5-n1etudlitt2190/500222ar/

Paz, Octavio, "Razón de ser”, Taller, 2 (abril de 1939), pp. 30-34. [Edición facsimilar recogida en Revistas literarias mexicanas modernas, México, FCE, 1982, 150-154].

El laberinto de la soledad, México, FCE, 1959 [1950].

El arco y la lira, México, FCE, 1956.

Libertad bajo palabra. Obra poética (1935-1958), México, FCE, 1960.

Corriente alterna, México, Siglo XXI Editores, 1967.

Las peras del olmo, Barcelona, Seix Barral, 1971.

Primeras letras (1931-1943), selección, introducción y notas de

Enrico Mario Santí, México, Vuelta, 1988. 
"El cántaro roto", en La estación violenta, Obras completas, t. XI, México, FCE, 1994 [1955], pp. 213-216.

"La casa de la presencia", en Obras completas, t. I, México, FCE, 1994, pp. 15-27.

Obras completas, t. VI. Los privilegios de la vista I: Arte moderno universal, México, FCE, 1994.

Obras completas, t. VII. Los privilegios de la vista II: Arte de México, México, FCE, 1994.

Reyes, Alfonso, “Las nuevas artes”, en Obras completas, México, FCE, 1959 [1944], t. IX, pp. 400-403.

Schärer-Nussberger, Maya, Octavio Paz: trayectorias y visiones, México, FCE, 1989.

Sheridan, Guillermo, Poeta con paisaje. Ensayos sobre la vida de Octavio Paz 1, México, Era, 2015 [2004].

Stanton, Anthony, El río reflexivo. Poesía y ensayo en Octavio Paz (19311958), México, El Colegio de México-FCE, 2015.

Torres Fierro, Danubio, "Itinerario de Octavio Paz" [reseña], Vuelta, 207 (febrero de 1994), pp. 36-38. Disponible en línea: https://www.letraslibres. com/vuelta/itinerario-octavio-paz

Weinberg, Liliana, "Luz inteligente: la dimensión antropológica en el ensayo temprano de Octavio Paz", en Héctor Jaimes, coord., Octavio Paz: La dimensión estética del ensayo, México, Siglo XXI Editores, 2004, pp. 269-311.

Pensar el ensayo, México, Siglo XXI Editores, 2007.

El ensayo en busca del sentido, México-Madrid-Berlín, CIALC-

Iberoamericana-Vervuert, 2014.

coord., El ensayo en diálogo, vol. I., México, CIALC, UNAM, 2017.

Zubiate, Jean-Pierre, "Essai et poésie au XXe siècle", en Pierre Glaudes, coord., L'essai: Métamorphoses d'un genre, Toulouse-Le Mirail, Presses Universitaires du Mirail, 2002, pp. 381-415. 
